\title{
Глобальные данные о фиторазнообразии Алтайской горной страны, представленные в мировых научных депозитариях
}

\section{Global data on phytodiversity of the Altai mountain country, presented in the world's scientific depositories}

\author{
Ваганов А. В. ${ }^{1,2}$, Шмаков А. И. ${ }^{1}$, Гудкова П. Д. ${ }^{1,3}$ \\ Vaganov A. V. ${ }^{1,2}$, Shmakov A. I. ${ }^{1}$, Gudkova P. D. ${ }^{1,3}$ \\ ${ }^{1}$ Алтайский государственный университет, г. Барнаул, Россия. E-mail: vaganov_vav@mail.ru \\ ${ }^{2}$ Сахалинский филиал Ботанического сада-института ДВО РАН, г. Южно-Сахалинск, Россия \\ ${ }^{3}$ Томский государственный университет, г. Томск, Россия \\ ${ }^{1}$ Altai State University, Barnaul, Russia \\ ${ }^{2}$ Sakhalin Branch of the Botanical Garden-Institute FEB RAS, Yuzhno-Sakhalinsk, Russia \\ ${ }^{3}$ Tomsk State University, Tomsk, Russia
}

\begin{abstract}
Peфepam. Алтайская горная страна (АГС) является самым высоким поднятием Северной Азии, её уровень биоразнообразия в три раза богаче Западной Сибири. Биоразнообразие территории АГС исследуется на протяжении двухсот лет. При этом наибольшее число находок приходится на последние 30 лет с момента детального изучения Алтайской горной страны специалистами Южно-Сибирского ботанического сада АлтГУ (Барнаул) под руководством Ботанического института им. В. Л. Комарова (Санкт-Петербург). В данном исследовании произведено ботанико-географическое районирование открытыми ГИС-системами (GeoJSON) территории АГС и выявлен список из 44 мировых научных депозитариев, содержащих в коллекции не менее 10 гербарных листов с территории АГС и представленных в глобальной информационной системе по биоразнообразию GBIF (Global Biodiversity Information Facility). Полученная информация служит основой для систематиков-исследователей флоры территории АГС для поиска местонахождений хранения материалов по своим объектам исследования, а также знакомством с их цифровой копией дистанционным способом. Описанный алгоритм является эффективным и может быть применен для других территорий.
\end{abstract}

Ключевые слова. Гербарий, база данных, GBIF, ГИС, ареал, флора, Алтайская горная страна, фиторазнообразие.

Summary. The Altai mountain country (AMC) is the highest uplift of North Asia, its biodiversity level is three times richer than Western Siberia. The biodiversity of the AMC territory has been explored for 200 years. At the same time, the greatest number of finds falls on the last 30 years since the beginning of a detailed study of the Altai mountainous country by specialists of the South-Siberian Botanical Garden of AltSU (Barnaul) under the guidance of the Botanical Institute named after. V. L. Komarova (St. Petersburg). In this study, botanical and geographical zoning by the open GIS systems (GeoJSON) of the AGS territory was made and a list of 44 world scientific depositories in the collection containing at least 10 herbarium sheets from the AMC territory and presented in the Global Biodiversity Information System GBIF (Global Biodiversity Information) Facility). The gained information serves as a basis for systematists-researchers of the AMC territory flora to search for locations of materials storage in their research objects, as well as familiarity with their digital copy by a remote method. The described algorithm is effective and can be applied for other territories.

Key words. Herbarium, database, GBIF, GIS, area, flora, Altai mountain country, phytodiversity.

Алтайская горная страна (АГС) среди континентальных горных стран Сибири (и в целом - в Северной и Центральной Азии) одновременно является и высочайшим современным поднятием, и наиболее благоприятным для развития органической жизни пространством в Сибири. За счет того, что здесь сочетаются широтно и меридианально простирающиеся межгорные котловины, хребты, высокогорные плато, районы типичных мелкосопочников и обширные нагорья, рельеф считается исключительно 
сложным (Камелин, 1998). Высшие точки АГС - двуглавая Белуха (4506 и 4400м) в Катунском хребте и горный узел Таван-Богдо-Ула (пять священных гор с 3 крупнейшими вершинами в 4374, 4360 и 3981 м). Это территория около 550000 кв. км в пределах России, Казахстана, Китая и Монголии. Огромное, сложно устроенное горное поднятие Алтая, с одной стороны, является крайним форпостом мощных горных систем юга Сибири и Северной Монголии, а, с другой, тесно связана с еще более мощными горными системами Тянь-Шаня (Флора Алтая, 2005).

Алтайская горная страна при своей относительно небольшой территориальной площади, включает большое число населяющих её биологических объектов. Девид Олсон и Эрик Динерштайн в своей работе «The global 200. Priority ecoregions for global conservation» относят территорию Алтая и Саян в числе 200 приоритетных экорегионов мира для глобального сохранения биоразнообразия (Olson, Dinersteinm, 2004). Они отмечают, что на $10 \%$ территории мира данных 200 экорегионов сосредоточено до $90 \%$ всего его биоразнообразия.

Ярким успешным примером интеграции разрозненных данных о биологическом разнообразии мира является глобальная информационная система по биоразнообразию (Global Biodiversity Information Facility - GBIF, http://www.gbif.org; Filippova et al., 2017). Система обмена информацией в GBIF построена на открытых стандартах, центральным из которых является Darwin Core (DwC), стандарт, разработанный специально для хранения данных по биоразнообразию. Четыре наиболее распространенных типа исходных данных в биологии по мировым стандартам сегодня должны публиковаться на следующих ресурсах: списки видов (ChecklistData) - GBIF; местонахождения отдельных особей (OccurrenceData) - GBIF; данные обследований на пробных площадях (SamplingeventData) - GBIF; последовательности белков и нуклеиновых кислот - GenBank, European Nucleotide Archive, Barcode of Life Data Systems и др.

Научные депозитарии, в число которых входят Гербарии, как правило, публикуют тип данных «OccurrenceData», которые содержат этикеточную информацию о нахождении того или иного вида в определенном месте в определенное время, то есть предполагают наличие сведений о дате находки и географической привязке (координатах) места нахождения вида (или сбора образца). На момент подготовки данной статьи в GBIF содержится 1090124220 записей из 42838 депозитариев мира, находящихся в 1365 научно-образовательных организациях (GBIF, 2019).

В целях объединения исследователей систематиков, изучающих флору АГС, в 2018 г. был разработан проект «Флора Алтая», размещенный в сети Интернет по адресy altaiflora.asu.ru. Сайт исполнен в Word Press, системе управления содержимым сайта с открытым исходным кодом. Для подготовки раздела, содержащего карту АГС (altaiflora.asu.ru/карта-агс/) с 19-ю ботанико-географическими районами по Р. В. Камелину (Флора Алтая, 2005), нами были прорисованы 19 полигонов с использованием плагина WP Google Maps (рис.). Основойдля нанесения полигонов послужили топографические карты в маситабе $1: 500000$.

Полученные наборы координат всех полигонов были отредактированы в современной спецификации создания географических структур GeoJSON. GeoJSON - открытый формат, предназначенный для хранения географических структур данных. Формат основан на JSON - (JavaScriptObjectNotation) текстовый формат обмена данными.

Была получена граница АГС, включающая 19 ботанико-географических районов (полигонов) в формате GeoJSON, с набором координат:

\{ "type": "Polygon", "coordinates": [ [[91.07, 53.27],[90.71, 53.32],[90.89, 53.50],[90.76, 53.60],[90.53, 53.62],[90.20, 53.84],[89.17, 53.44],[88.91, 53.62],[87.52, 53.72],[87.30, 53.61],[87.19, 53.35],[86.54, 53.22],[86.39, 53.07],[86.48, 52.91],[86.67, 52.78],[86.25, 52.60],[85.91, 52.64],[85.70, 52.39],[85.46, 52.19],[84.52, 52.04],[83.54, 51.95],[82.53, 51.88],[81.49, 51.42],[80.90, 50.74],[80.99, 50.35],[80.88, 49.87],[81.18, 49.59],[82.03, 49.28],[80.95, 48.92],[80.41, 48.33],[80.46, 47.98],[79.58, 47.70],[79.55, 47.43],[80.28, 47.25],[80.53, 47.09],[81.44, 46.78],[82.10, 46.66],[82.37, 46.30],[82.74, 46.67],[83.82, 46.41],[83.89, 46.21],[84.33, 46.24],[85.17, 46.38],[85.88, 46.53],[86.33, 46.45],[86.93, 46.49],[87.37, 46.93],[86.87, 47.28],[87.49, 47.40],[87.31, 47.53],[87.52, 47.73],[88.41, 47.37],[88.53, 47.21],[89.55, 46.33],[90.22, 45.68],[90.17, 45.39],[90.57, 45.09],[91.25, 44.83],[91.66, 44.76],[91.96, 44.88],[93.06, 44.87],[93.77, 44.79],[94.43, 44.83],[95.03, 44.53],[95.37, 44.45],[95.86, 44.53],[95.96, 44.79],[96.11, 44.77],[96.17, 44.88],[96.25, 45.17],[96.95, 45.06],[97.97, 44.69],[98.68, 44.56],[99.10, 44.60],[99.08, 45.00],[99.11, 45.20],[98.90, 45.48],[98.65, 45.63],[97.98, 45.64],[97.94, 45.90],[97.22, 46.30],[96.28, 46.87],[95.79, 47.34],[95.45, 47.41],[94.81, 
47.33],[94.85, 46.69],[92.00, 48.25],[92.42, 48.42],[92.44, 48.63],[92.03, 49.77],[91.64, 50.36],[92.07, 50.70],[91.37, $51.45],[92.25,51.75],[92.01,51.95],[92.33,52.11],[92.52, \quad 52.36],[92.34,52.60],[91.87, \quad 52.87],[91.07,53.27]]]\}$

Расширение GeoJSON адаптировано для GBIF (пункт «Location» в разделе «search/occurrences»). Используя полученный набор данных по полигону, можно осуществлять выгрузку данных о местонахождении объектов по любой группе живых организмов с территории АГС, внесенных в GBIF.

Произведя выгрузку данных в разделе «search/occurrences» из базы данных GBIF по полигону АГС в подпункте «Metrics», был получен список из 44 мировых научных депозитариев из 42838 возможных, содержащих в гербарном фонде более 10 находок с территории АГС. Самая первая запись является ботанической и датируется 1791 г. (https://www.gbif.org/occurrence/437367318) и хранится в Музее натуральной истории в Париже.

Подготовленная нами таблица содержит информацию о научных депозитариях, в которых хранятся цифровые копии гербарных листов, включая этикеточную информацию, собранные за более чем двухсотлетний период исследования территории АГС. Список депозитариев дополнен сведениями об издателе (организация-координатор данных для GBIF) либо организации (в случае трансконтинентальных проектов), номере DOI метаданных Dataset, а также стране и депозитарии (владельце хостинга). Сведения об объемах коллекций не приводятся ввиду данамичного наполнения депозитариев записями, несущими цифровое изображение и геопривязки. При этом каждый исследователь может самостоятельно по названию интересующего его депозитария и полигона GeoJSON АГС получить актуальные сведения по любому таксону.

Таблица

Сведения о научных депозитариях, содержащих информацию о находках растений с территории Алтайской горной страны, размещенных в глобальной информационной системе по биоразнообразию (Global Biodiversity Information Facility - GBIF).

\begin{tabular}{|c|c|c|c|c|c|}
\hline № & $\begin{array}{c}\text { Научный депозита- } \\
\text { рий (Dataset) }\end{array}$ & $\begin{array}{l}\text { Организация изда- } \\
\text { тель (Publishedby) }\end{array}$ & DOI & $\begin{array}{c}\text { Страна/op- } \\
\text { ганизация } \\
\text { (Country/ } \\
\text { Organization) } \\
\end{array}$ & $\begin{array}{c}\text { Владелец хостинга } \\
\text { (Hostedby) }\end{array}$ \\
\hline & $\begin{array}{l}\text { A global database for } \\
\text { the distributions of } \\
\text { crop wild relatives }\end{array}$ & $\begin{array}{c}\text { Centro Internacional } \\
\text { de Agricultura } \\
\text { Tropical (CIAT) }\end{array}$ & 10.15468/jyrthk & Norway & $\begin{array}{c}\text { Natural History } \\
\text { Museum, University } \\
\text { of Oslo }\end{array}$ \\
\hline & $\begin{array}{c}\text { Bruce Bennett } \\
\text { Herbarium (BABY) }\end{array}$ & $\begin{array}{c}\text { Consortium of Pacific } \\
\text { Northwest Herbaria }\end{array}$ & $10.5886 / \mathrm{cp} 1 \mathrm{vgz}$ & Canada & $\begin{array}{c}\text { Université de } \\
\text { Montréal Biodiversity } \\
\text { Centre } \\
\end{array}$ \\
\hline & $\begin{array}{l}\text { Bryophyte herbarium } \\
\text { TRH, NTNU Univer- } \\
\text { sity Museum }\end{array}$ & $\begin{array}{l}\text { NTNU University } \\
\text { Museum }\end{array}$ & 10.15468/zxu8zu & Norway & $\begin{array}{c}\text { Natural History } \\
\text { Museum, University } \\
\text { of Oslo }\end{array}$ \\
\hline & Carnet en Ligne & Tela Botanica & $10.15468 /$ ryden 2 & Tela Botanica & Tela Botanica \\
\hline & CAS Botany (BOT) & $\begin{array}{c}\text { California Academy } \\
\text { of Sciences }\end{array}$ & $10.15468 / 7$ gudyo & $\begin{array}{c}\text { United Statesof } \\
\text { America } \\
\end{array}$ & $\begin{array}{c}\text { California Academy } \\
\text { of Sciences }\end{array}$ \\
\hline & CRIS dataset & CRIS & 10.15468/zychiy & $\begin{array}{l}\text { Russian } \\
\text { Federation }\end{array}$ & $\begin{array}{c}\text { Institute of Math- } \\
\text { ematical Problems } \\
\text { of Biology, Russian } \\
\text { Academy of Sciences }\end{array}$ \\
\hline & $\begin{array}{l}\text { CSIC-Real Jardín Bo- } \\
\text { tánico-Colección de } \\
\text { Musgos (MA-Musci) }\end{array}$ & $\begin{array}{l}\text { CSIC-Real Jardín- } \\
\text { Botánico }\end{array}$ & 10.15468/aj41tg & Spain & GBIF-Spain \\
\hline & $\begin{array}{l}\text { EURISCO, The Euro- } \\
\text { pean Genetic Resourc- } \\
\text { es Search Catalogue }\end{array}$ & $\begin{array}{l}\text { Bioversity Interna- } \\
\text { tional }\end{array}$ & 10.15468/a3lnmd & Italy & $\begin{array}{l}\text { Bioversity Interna- } \\
\text { tional }\end{array}$ \\
\hline
\end{tabular}


Таблица (продолжение)

\begin{tabular}{|c|c|c|c|c|}
\hline $\begin{array}{l}\text { Family Primulaceae } \\
\text { in Virtual Herbaria of } \\
\text { CSBG SB RAS (NS) }\end{array}$ & $\begin{array}{c}\text { Central Siberian } \\
\text { Botanical Garden SB } \\
\text { RAS }\end{array}$ & 10.15468/yivohq & $\begin{array}{l}\text { Russian } \\
\text { Federation }\end{array}$ & $\begin{array}{l}\text { Institute of Math- } \\
\text { ematical Problems } \\
\text { of Biology, Russian } \\
\text { Academy of Science }\end{array}$ \\
\hline $\begin{array}{c}\text { Geneva Herbarium - } \\
\text { De Candolle's Prodro- } \\
\text { mus (G-DC) }\end{array}$ & $\begin{array}{l}\text { Conservatoire et Jar- } \\
\text { dinbotaniques de la } \\
\text { Ville de Genève - G }\end{array}$ & 10.15468/s5auru & Switzerland & $\begin{array}{l}\text { Conservatoire et Jar- } \\
\text { dinbotaniques de la } \\
\text { Ville de Genève - G }\end{array}$ \\
\hline $\begin{array}{l}\text { Geneva Herbarium } \\
\text { - General Collection } \\
\text { (G) }\end{array}$ & $\begin{array}{l}\text { Conservatoire et Jar- } \\
\text { dinbotaniques de la } \\
\text { Ville de Genève - G }\end{array}$ & 10.15468/rvjdu1 & Switzerland & $\begin{array}{l}\text { Conservatoire et Jar- } \\
\text { dinbotaniques de la } \\
\text { Ville de Genève - G }\end{array}$ \\
\hline $\begin{array}{l}\text { Geographicallytagged } \\
\text { INSDC sequences }\end{array}$ & $\begin{array}{c}\text { European Molecular } \\
\text { Biology Laboratory } \\
\text { (EMBL) }\end{array}$ & $10.15468 /$ cndomv & $\begin{array}{l}\text { EMBL-EBI, } \\
\text { NCBI, DDBJ }\end{array}$ & $\begin{array}{c}\text { European Molecular } \\
\text { Biology Laboratory } \\
\text { (EMBL) }\end{array}$ \\
\hline HerbariumBerolinense & $\begin{array}{l}\text { Botanic Garden and } \\
\text { Botanical Museum } \\
\text { Berlin-Dahlem }\end{array}$ & 10.15468/dlwwhz & Germany & $\begin{array}{c}\text { Botanic Garden and } \\
\text { Botanical Museum } \\
\text { Berlin-Dahlem }\end{array}$ \\
\hline Herbarium GAT & $\begin{array}{c}\text { Leibniz Institute of } \\
\text { Plant Genetics and } \\
\text { Crop Plant Research } \\
\text { (IPK) }\end{array}$ & 10.15468/hiiw6b & Germany & $\begin{array}{c}\text { Leibniz Institute of } \\
\text { Plant Genetics and } \\
\text { Crop Plant Research } \\
\text { (IPK) }\end{array}$ \\
\hline $\begin{array}{c}\text { Herbarium } \\
\text { Senckenbergianum } \\
\text { (FR) }\end{array}$ & Senckenberg & 10.15468/ucmdjy & Germany & Senckenberg \\
\hline $\begin{array}{l}\text { iNaturalist Research- } \\
\text { gradeObservations }\end{array}$ & iNaturalist.org & $10.15468 / a b 3 s 5 x$ & iNaturalist & iNaturalist.org \\
\hline $\begin{array}{c}\text { Lund Botanical Muse- } \\
\text { um (LD) }\end{array}$ & $\begin{array}{l}\text { Lund Botanical Mu- } \\
\text { seum (LD) }\end{array}$ & $10.15468 / \mathrm{c} 4 \mathrm{w} 4 \mathrm{co}$ & Sweden & GBIF-Sweden \\
\hline MEL AVH data & $\begin{array}{c}\text { Australia's Virtual } \\
\text { Herbarium }\end{array}$ & 10.15468/rhzrxw & Australia & $\begin{array}{c}\text { Atlas of Living } \\
\text { Australia }\end{array}$ \\
\hline $\begin{array}{l}\text { Moscow University } \\
\text { Herbarium (MW) }\end{array}$ & $\begin{array}{l}\text { Lomonosov Moscow } \\
\text { State University }\end{array}$ & 10.15468/cpnhcc & $\begin{array}{c}\text { Russian } \\
\text { Federation }\end{array}$ & $\begin{array}{l}\text { Lomonosov Moscow } \\
\text { State University }\end{array}$ \\
\hline $\begin{array}{l}\text { Natural History Muse- } \\
\text { um (London) Collec- } \\
\text { tion Specimens }\end{array}$ & $\begin{array}{l}\text { Natural History } \\
\text { Museum }\end{array}$ & $10.5519 / 0002965$ & $\begin{array}{l}\text { United } \\
\text { Kingdom }\end{array}$ & $\begin{array}{l}\text { Natural History } \\
\text { Museum }\end{array}$ \\
\hline $\begin{array}{c}\text { Natural History Muse- } \\
\text { um, Vienna - Herbar- } \\
\text { ium W }\end{array}$ & $\begin{array}{c}\text { Natural History } \\
\text { Museum, Vienna - } \\
\text { Herbarium W } \\
\end{array}$ & $10.15468 / 5 \mathrm{~s} 17 \mathrm{sh}$ & Austria & $\begin{array}{c}\text { Natural History } \\
\text { Museum, Vienna - } \\
\text { Herbarium W } \\
\end{array}$ \\
\hline $\begin{array}{l}\text { Paleobiology } \\
\text { Database }\end{array}$ & $\begin{array}{c}\text { Paleobiology } \\
\text { Database }\end{array}$ & 10.15468/jfqhiu & $\begin{array}{c}\text { United Statesof } \\
\text { America }\end{array}$ & VertNet \\
\hline $\begin{array}{l}\text { Paleobiology } \\
\text { Database }\end{array}$ & $\begin{array}{l}\text { Marine Science } \\
\text { Institute, UCSB }\end{array}$ & 10.15468/2durgn & $\begin{array}{c}\text { United Statesof } \\
\text { America }\end{array}$ & $\begin{array}{l}\text { Marine Science } \\
\text { Institute, UCSB }\end{array}$ \\
\hline $\begin{array}{l}\text { Phanerogamic Botani- } \\
\text { cal Collections (S) }\end{array}$ & GBIF-Sweden & $\begin{array}{c}10.15468 / \\
\text { yo3mmu }\end{array}$ & Sweden & GBIF-Sweden \\
\hline $\begin{array}{l}\text { Plant Specimen from } \\
\text { Herbarium (CDBI) } \\
\text { in China, Chengdu } \\
\text { Institute of Botany, } \\
\text { Chinese Academy of } \\
\text { Sciences } \\
\end{array}$ & $\begin{array}{l}\text { Chinese Academy of } \\
\text { Sciences (CAS) }\end{array}$ & 10.15468/pui83d & Chine & $\begin{array}{l}\text { Chinese Academy of } \\
\text { Sciences (CAS) }\end{array}$ \\
\hline $\begin{array}{l}\text { Plant Specimen from } \\
\text { Herbarium (IBK) in } \\
\text { China, Guangxi Insti- } \\
\text { tute of Botany, }\end{array}$ & $\begin{array}{l}\text { Chinese Academy of } \\
\text { Sciences (CAS) }\end{array}$ & $10.15468 / \mathrm{dk} 5 \mathrm{gko}$ & China & $\begin{array}{l}\text { Chinese Academy of } \\
\text { Sciences (CAS) }\end{array}$ \\
\hline
\end{tabular}


Таблица (продолжение)

\begin{tabular}{|c|c|c|c|c|}
\hline $\begin{array}{c}\text { Chinese Academy of } \\
\text { Sciences }\end{array}$ & & & & \\
\hline $\begin{array}{l}\text { Plant Specimen from } \\
\text { Herbarium (NAS) } \\
\text { in China, Institute } \\
\text { of Botany, Jiangsu } \\
\text { Province and Chinese } \\
\text { Academy of Sciences }\end{array}$ & $\begin{array}{l}\text { Chinese Academy of } \\
\text { Sciences (CAS) }\end{array}$ & $10.15468 / \mathrm{r} 2 \mathrm{la} 8 \mathrm{~h}$ & China & $\begin{array}{c}\text { Chinese Academy of } \\
\text { Sciences (CAS) }\end{array}$ \\
\hline $\begin{array}{l}\text { Polish gene bank- } \\
\text { passport data of plants } \\
\text { accessions which are } \\
\text { important in human } \\
\text { life }\end{array}$ & $\begin{array}{l}\text { Plant Breeding and } \\
\text { Acclimatization Insti- } \\
\text { tute (IHAR) - Nation- } \\
\text { al Research Institute }\end{array}$ & 10.15468/uwiswv & Poland & $\begin{array}{l}\text { University of } \\
\text { Warsaw, Dept. of } \\
\text { Ecology }\end{array}$ \\
\hline $\begin{array}{c}\text { Polish seed gene bank } \\
\text { - historical passport } \\
\text { data of accessions }\end{array}$ & $\begin{array}{l}\text { Plant Breeding and } \\
\text { Acclimatization Insti- } \\
\text { tute (IHAR) - Nation- } \\
\text { al Research Institute }\end{array}$ & $10.15468 / 71$ entb & Poland & $\begin{array}{l}\text { University of } \\
\text { Warsaw, Dept. of } \\
\text { Ecology }\end{array}$ \\
\hline $\begin{array}{l}\text { Pollen record of a } \\
\text { sediment profile from } \\
\text { Lake Teletskoye }\end{array}$ & $\begin{array}{l}\text { PANGAEA - Pub- } \\
\text { lishing Network for } \\
\text { Geoscientific and } \\
\text { Environmental Data }\end{array}$ & $\begin{array}{c}10.1594 / \\
\text { pangaea. } 726701\end{array}$ & PANGAEA & $\begin{array}{l}\text { PANGAEA - Pub- } \\
\text { lishing Network for } \\
\text { Geoscientific and } \\
\text { Environmental Data }\end{array}$ \\
\hline $\begin{array}{l}\text { Royal BC Museum - } \\
\text { Herbarium (V) }\end{array}$ & $\begin{array}{c}\text { Royal British } \\
\text { Columbia Museum }\end{array}$ & 10.5886/yxupar & Canada & $\begin{array}{c}\text { Université de Mon- } \\
\text { tréal Biodiversity } \\
\text { Centre }\end{array}$ \\
\hline $\begin{array}{l}\text { Royal Botanic Garden } \\
\text { Edinburgh Living } \\
\text { Plant Collections (E) }\end{array}$ & $\begin{array}{l}\text { Royal Botanic } \\
\text { Garden Edinburgh }\end{array}$ & 10.15468/bkzv1l & $\begin{array}{l}\text { United } \\
\text { Kingdom }\end{array}$ & $\begin{array}{l}\text { Royal Botanic } \\
\text { Garden Edinburgh }\end{array}$ \\
\hline $\begin{array}{l}\text { Royal Botanic Gar- } \\
\text { dens, Kew - Herbari- } \\
\text { um Specimens }\end{array}$ & $\begin{array}{l}\text { Royal Botanic Gar- } \\
\text { dens, Kew }\end{array}$ & $10.15468 / \operatorname{ly} 60 \mathrm{bx}$ & $\begin{array}{l}\text { United } \\
\text { Kingdom }\end{array}$ & $\begin{array}{l}\text { Royal Botanic Gar- } \\
\text { dens, Kew }\end{array}$ \\
\hline $\begin{array}{l}\text { Rye, Barley, Oats } \\
\text { Genetic Resources. } \\
\text { N.I.Vavilov Research } \\
\text { Institute of Plant In- } \\
\text { dustry, St. Petersburg }\end{array}$ & $\begin{array}{l}\text { N. I. Vavilov Insti- } \\
\text { tute of Plant Genetic } \\
\text { Resources (VIR) }\end{array}$ & 10.15468/spmpkr & $\begin{array}{l}\text { Russian } \\
\text { Federation }\end{array}$ & $\begin{array}{l}\text { N. I. Vavilov Insti- } \\
\text { tute of Plant Genetic } \\
\text { Resources (VIR) }\end{array}$ \\
\hline $\begin{array}{c}\text { Tallinn Botanic } \\
\text { Garden }\end{array}$ & PlutoF & $\begin{array}{c}10.15156 / \\
\text { bio/587443 }\end{array}$ & Estonia & PlutoF \\
\hline $\begin{array}{l}\text { The New York Botani- } \\
\text { cal Garden Herbarium } \\
\text { (NY) }\end{array}$ & $\begin{array}{l}\text { The New York Botan- } \\
\text { ical Garden }\end{array}$ & 10.15468/6e8nje & $\begin{array}{l}\text { United States of } \\
\text { America }\end{array}$ & $\begin{array}{l}\text { The New York Botan- } \\
\text { ical Garden }\end{array}$ \\
\hline $\begin{array}{l}\text { The vascular plants } \\
\text { collection (P) at the } \\
\text { Herbarium of the } \\
\text { Muséum national } \\
\text { d'HistoireNaturelle } \\
\text { (MNHN - Paris) }\end{array}$ & $\begin{array}{l}\text { MNHN - Mu- } \\
\text { seum national } \\
\text { d'Histoirenaturelle }\end{array}$ & $10.15468 /$ nc6rxy & France & $\begin{array}{l}\text { MNHN - Mu- } \\
\text { seum national } \\
\text { d'Histoirenaturelle }\end{array}$ \\
\hline $\begin{array}{c}\text { Tropicos Specimen } \\
\text { Data }\end{array}$ & $\begin{array}{l}\text { Missouri Botanical } \\
\text { Garden }\end{array}$ & 10.15468/hja69f & $\begin{array}{c}\text { United Statesof } \\
\text { America }\end{array}$ & $\begin{array}{c}\text { Missouri Botanical } \\
\text { Garden }\end{array}$ \\
\hline $\begin{array}{l}\text { UAM Herbarium } \\
\text { (ALA), Cryptogam } \\
\text { Collection (Arctos) }\end{array}$ & $\begin{array}{l}\text { University of Alaska } \\
\text { Museum of the North }\end{array}$ & $10.15468 / \mathrm{bdwzth}$ & $\begin{array}{l}\text { United Statesof } \\
\text { America }\end{array}$ & $\begin{array}{l}\text { University of Alaska } \\
\text { Museum of the North }\end{array}$ \\
\hline
\end{tabular}


«Проблемы ботаники Южной Сибири и Монголии» - XVIII Международная научно-практическая конференция

Таблица (окончание)

\begin{tabular}{|c|c|c|c|c|}
\hline $\begin{array}{l}\text { United States Nation- } \\
\text { al Plant Germplasm } \\
\text { System Collection }\end{array}$ & $\begin{array}{l}\text { US National Plant } \\
\text { Germplasm System }\end{array}$ & $10.15468 /$ ce 7 fox & $\begin{array}{l}\text { United Statesof } \\
\text { America }\end{array}$ & $\begin{array}{l}\text { US National Plant } \\
\text { Germplasm System }\end{array}$ \\
\hline $\begin{array}{c}\text { University of British } \\
\text { Columbia Herbarium } \\
\text { (UBC) - Bryophytes } \\
\text { Collection }\end{array}$ & $\begin{array}{l}\text { University of British } \\
\text { Columbia }\end{array}$ & $10.5886 / 5 \mathrm{rr} 9 \mathrm{fbb} 6$ & Canada & $\begin{array}{c}\text { Université de Mon- } \\
\text { tréal Biodiversity } \\
\text { Centre }\end{array}$ \\
\hline $\begin{array}{l}\text { University of Michi- } \\
\text { gan Herbarium }\end{array}$ & $\begin{array}{l}\text { University of Michi- } \\
\text { gan Herbarium }\end{array}$ & $10.15468 /$ nl8bvi & $\begin{array}{l}\text { United States of } \\
\text { America }\end{array}$ & $\begin{array}{c}\text { University of } \\
\text { Michigan College of } \\
\text { Literature, Science } \\
\text { \& Arts } \\
\end{array}$ \\
\hline $\begin{array}{l}\text { University of Vienna, } \\
\text { Institute for Botany - } \\
\text { Herbarium WU }\end{array}$ & $\begin{array}{c}\text { University of Vienna, } \\
\text { Institute for Botany - } \\
\text { Herbarium WU }\end{array}$ & 10.15468/tnj8wm & Austria & $\begin{array}{c}\text { University of Vienna, } \\
\text { Institute for Botany - } \\
\text { Herbarium WU }\end{array}$ \\
\hline $\begin{array}{l}\text { Virtual Herbarium } \\
\text { ALTB (South-Siberian } \\
\text { Botanical Garden) }\end{array}$ & Altai State University & $\begin{array}{l}10.15468 / \\
\text { y6xmme }\end{array}$ & $\begin{array}{l}\text { Russian } \\
\text { Federation }\end{array}$ & $\begin{array}{c}\text { Institute of } \\
\text { Mathematical } \\
\text { Problems of Biology, } \\
\text { Russian Academy of } \\
\text { Sciences }\end{array}$ \\
\hline
\end{tabular}

В Алтайском государственном университете крупнейшим поставщиком данных в GBIF о растениях АГС является Гербарий ALTB (Vaganov, 2018).

Исследование выполнено при финансовой поддержке РФФИ в рамках научного проекта № 1944-220004_p_a

\section{ЛИТЕРАТУРА}

Камелин Р. В. Материалы по истории флоры Азии. - Барнаул: Изд-во Алтайского гос. ун-та, 1998. - 239 с. Флора Алтая / Коллектив авторов. Т. 1. Отв. ред. и ред. тома Р. В. Камелин. - Барнаул: АзБука, 2005. - 340 с.

Filippova N. V., Filippov I. V., Schigel D. S., Ivanova N. V., Shashkov M. P. Biodiversity informatics: global trends, national perspective and regional progress in Khanty-Mansi Autonomous Okrug // Environmental dynamics and global climate change, 2017. - Vol. 8, № 2. - C. 46-56.

GBIF - Global Biodiversity Information Facility. URL: http://www.gbif.org (accessed on 10.03.2019).

Olson D. M., Dinerstein E. The global 200: Priority ecoregions for global conservation // Annals of the Missouri Botanical Garden, 2002. - Vol. 89, № 2. - P. 199-224.

Vaganov A. V. Prospects for studying and preserving the biodiversity of the Altai-Sayan ecoregion in the context of the development of open databases // Ukrainian Journal of Ecology, 2018. - Vol. 8, № 2. -P. 380-382. DOI: $10.15421 / 2018 \_357$ 